\section{Rita Gnutzmann:}

Catedrática de Literatura Hispanoamericana en la Universidad del País Vasco. Su investigación se centra en la literatura argentina desde el siglo XIX y la peruana del siglo XX. Dentro de estos campos ha publicado libros sobre La novela naturalista en Argentina (Rodopi, 1998), Julio Cortázar, Guía de lectura de Rayuela (Alhambra. 1989), Roberto Arlt, Innovación y compromiso (Univ. de Lérida, 2004), Mario Vargas Llosa, Cómo leer a Mario Vargas Llosa (Júcar, 1992) y la prosa peruana, Novela y cuento del siglo XX en el Perú (Cuadernos de América Sin Nombre, 2007). Además ha editado textos de Florencio Sánchez, Eugenio Cambaceres, Roberto Arlt, Pablo de Rokha, Ramón Griffero y César de María.

\section{1}

Sebastián Salazar Bondy, Lima la horrible, Lima, Populibros, s.f., p. 16.

2

José Miguel Oviedo, La invención de una realidad, Barcelona, Seix Barral, 1982, p. 55.

3

Enrique Congrains Martín, Lima, hora cero, Lima, Círculo de novelistas peruanos, 1955 y No una, sino muchas muertes, Barcelona, Planeta, 1975.

Para las citas, sigo siempre las ediciones que se encuentran en las notas, indicando la p. entre paréntesis.

Una retrospectiva sobre medio siglo de narrativa peruana

RITA GNUTZMANN

\title{
UNA RETROSPECTIVA SOBRE MEDIO SIGLO DE NARRATIVA PERUANA
}

\author{
RITA GNUTZMANN
}

Facultad de Letras, Vitoria

Comenzaré esta exposición con los escritores que publicaron a mediados del siglo pasado, la llamada «Generación del 50». La temática de estos escritores es predominantemente urbana y aborda la situación precaria de las clases bajas y el lumpen (Enrique Congrains) o de la clase media en peligro de descenso social (Sebastián Salazar Bondy, Oswaldo Reynoso, Luis Loayza y Carlos Eduardo Zavaleta, quien se ocupa también del mundo del serrano). Todos ellos están influidos por las ideas socialistas de Mariátegui y la experiencia de -en algún caso incluso la lucha contra- la dictadura del General Odría que sofocó el país entre 1948 y 1956 y que fue la fuente de inspiración para Conversación en la Catedral de Vargas Llosa. Asimismo hay que tener presentes los cambios que sufrió la capital en aquellos años: si Lima tenía 645 mil habitantes en 1940, en 1961 contaba con 1.846 .000 y para finales de los años 50 los sociólogos ya registraban 56 barriadas en la capital. Salazar Bondy nos ofrece una imagen de la Lima de entonces en su ensayo Lima la horrible: «El embotellamiento de vehículos en el centro y las avenidas, la ruda competencia de buhoneros y mendigos, las fatigadas colas ante los incapaces medios de transporte, la crisis del alojamiento, los aniegos debidos a las tuberías que estallan...» ${ }^{1}$. Con la «Generación del 50» se introducen en la novela peruana las técnicas modernas de Joyce y Faulkner y el estilo depurado de Hemingway. Sin embargo, su objetivo social y de denuncia no les permite liberarse del realismo decimonónico o como explica José Miguel Oviedo: mientras estos escritores creen «en la virtualidad socialmente redentora de la literatura, [Vargas
Llosa] pudo darse cuenta de que su literatura no debía ser retratista, sino inventora y mítica, desinteresada, sin 'tesis'»'.

Al ser imposible abordar el conjunto de obras de esta generación, me centraré aquí en una novela de Enrique Congrains y otra de Oswaldo Reynoso para mostrar los logros de aquel grupo.

En 1954, Congrains publica el libro de cuentos Lima, hora cero ${ }^{3}$ en el que introduce la problemática vida en las barriadas limeñas de los que llegaron de otras partes del país, llenos de esperanza de una mejor vida. Todos ellos terminan frustrados y explotados, como el joven e ingenuo protagonista de «El niño de junto al cielo» quien será estafado por otro chico de la calle, más experimentado, que le quita los diez pesos con el pretexto de invertirlos en un negocio conjunto de compra-venta de revistas. Naturalmente el nuevo «amigo» se esfuma con el dinero y el joven provinciano ha aprendido su primera lección sobre la engañosa metrópoli y el capitalismo. También su única novela No una, sino muchas muertes (1958) está ubicada en una barriada y denuncia la violencia, la delincuencia y la explotación. Narra dos días en la vida de Maruja, de diecisiete años, que trabaja en un lavadero de pomos, regentado por una vieja avara y un matón zambo. Aunque Congrains retome el consabido tema de la lucha por el ascenso social, tan frecuente en el relato realista-naturalista del siglo XIX, en la novela éste adquiere un nuevo matiz al ser una mujer la protagonista. El comienzo de la novela, con Maruja observando los alrededores desde un basural, describe eficazmente tanto el medio ambiente como el condicionamiento de la 
joven: «al fondo [...] el barranquito que daba al acequión [...] a su derecha el mísero conjunto de chozas de adobe y estera [...] y a su izquierda, las chimeneas del barrio industrial» (p. 17). Maruja quisiera liberarse de este condicionamiento como también rechaza el lamento inútil de la madre que parece anticipar el leitmotiv de Zavalita de Conversación en la Catedral: «Todo es una joda. Joda desde que una nace, joda hasta que una revienta» (p. 29). Pero ni su coraje ni su búsqueda de valores por encima de las simples necesidades materiales -su «afán de perfeccionamiento y superación» (p. 32)- son suficientes para conseguir su objetivo. Pretende inculcar su propio afán en los hombres que la rodean, pero éstos sólo están interesados en cosas inmediatas como el alcohol, el sexo y el dinero rápido. Maruja realmente es más 'macho' que los hombres en general y que el débil y cobarde Alejandro en particular, al que ha elegido como amante y compañero de su gran plan: secuestrarle a la vieja los veinte locos esclavizados para establecer su propio lavadero. Pero ni Alejandro ni el resto de la pandilla están a la altura de sus planes; todos ellos prefieren el botín seguro de los ahorros de la vieja, robados por el zambo, en vez de invertir en un futuro a largo plazo como es un establecimiento propio. A pesar de su derrota debida a la inercia y el «inmediatismo» de los demás, Maruja no se resigna sino que, al final, avanza hacia la gran ciudad «a pleno aire con la dura compañía de [sus] manos acrecentadas». Algunos símbolos en torno a Maruja refuerzan la idea de un carácter extraordinario, como su gorrita roja, el tubo fluorescente (encontrado al comienzo y roto al final), la llama y el fuego. Si algunos críticos han visto en Maruja una persona definitivamente fracasada, a mi parecer, la última frase antes citada y su voluntad de «subir» y de «agigantarse» (p. 73) dejan un final abierto hacia futuras victorias.

Aunque la estructura es tradicional, con un desarrollo cronológico y un lenguaje del narrador que resulta a ratos artificial, no le faltan aciertos como las descripciones del ambiente o de personajes de los que son buena muestra la vieja y el zambo: «la abominable pareja, él emanando su fétido aliento y sudando grasa [... y ella], la maligna dueña de [...] astutamente calculadores ojos de vieja rata metálica» (p. 107), el personaje de Maruja, el argot de los jóvenes delincuentes e incluso algún intento embriónico de la corriente de la conciencia (la vista del tubo fluorescente que enmarca sus pensamientos entre las pp. 27-34).

En su primera novela Los inocentes (1961), reeditada como Lima en rock (Los inocentes) ${ }^{4}$, Oswaldo Reynoso se ocupa de los jóvenes limeños de clase media. Sus adolescentes se mueven en los ambientes públicos de «medio pelo»: parques, bares y billares, prostíbulos, la calle en general y podían constituir un antecedente de los protagonistas que Oscar Malca, treinta años más tarde, plasma en $\mathrm{Al}$ final de la calle (1993). En el primer libro de Reynoso, constituido por cinco breves textos unidos por el tema y los personajes que pertenecen a la misma pandilla, la influencia de la «Beat Generation» norteamericana resulta obvia. El tema de las cinco historias es la voluntad de los adolescentes de ser «hombre». En el primer capítulo, «Cara de Ángel», se establecen las normas que rigen las acciones de los jóvenes: «Hay que ser valiente, pendejo. Hay que saber fumar, chupar, jugar, robar, faltar al colegio, sacar plata a maricones y acostarse con putas» (p. 16). «El Rosquita» ofrece la descripción más detallada de estos «rocanroleros»: cabello negro alborotado, ojos niños y tristes; cigarrillo, que se cae de la boca, casaca roja y pantalón negro. Todos han sucumbido o van a sucumbir como Rosquita, algo más joven, a la seducción de la capital: «Porque en Lima está la tentación [...]: billares, cine, carreras, cantinas. Y el dinero. Sobre todo el dinero» (p. 70).

Pero la novela más innovadora de Reynoso es En octubre no hay milagros (1965), que narra en contrapunto las experiencias de dos grupos sociales: don Lucho Colmenares, pequeño empleado de Banca (cf. su apellido) en busca desesperada de un hogar para su familia, y don Manuel, dueño del Banco del Perú, empresario e influyente político, manipulador de todas las 'fuerzas vivas' del país a las que reúne en su casa en Ancón para preparar un complot contra el actual gobierno con el objetivo de conseguir otro más propicio para sus intereses. Sigue la consigna de su padre de gobernar «a este pueblo de zambos, indios y cholos [por la] fuerza: hambre, cárcel y bala» ${ }^{5}$. A la misma trama de don Lucho pertenecen los destinos de su mujer doña María y de sus hijos Bety, Carlos (alias «Zorro») y Miguel
4

Oswaldo Reynoso, Lima en rock (Los inocentes), Lima, Populibros, s.f.

5

Oswaldo Reynoso, En octubre no hay milagros, Lima, Edics. Wuaman Puma, 1965, p. 49.

Una retrospectiva sobre medio siglo de narrativa peruana RITA GNUTZMANN 


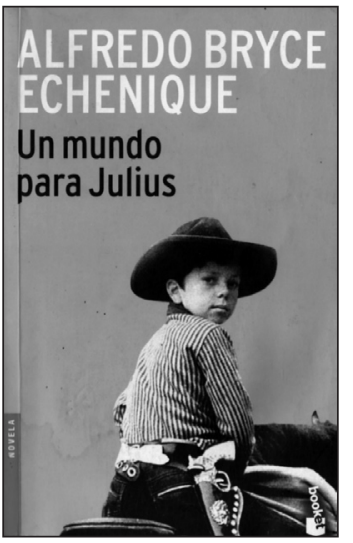

6

Cf. James Higgins, A History of Peruvian Literature, Liverpool, Francis Cairns, 1987, p. 21; Ana María Alfaro-Alexander, Hacia la modernización de la narrativa peruana. El Grupo Palermo, New York, Peter Lang 1991 , pp. 87 y ss.

\section{7}

Julio Ramón Ribeyro, La tentación del fracaso. Diario personal, 3 vols., Lima, Jaime Campodónico, 1992, 1993, 1995; vol. I, pp. 59, 61

8

En este cuento se describen los cambios de Miraflores: «De lugar de reposo y baños de mar, se había convertido en una ciudad moderna, cruzada por anchas avenidas de asfalto. Las viejas mansiones republicanas de las avenidas Pardo, Benavides, Grau, Ricardo Palma, Leuro y de los malecones, habían sido implacablemente demolidas para construir en los solares edificios de departamentos de diez y quince pisos, con balcones de vidrio y garajes subterráneos», Julio Ramón Ribeyro, Cuentos completos, Madrid, Alfaguara, 1994 , p. 422.

Una retrospectiva sobre medio siglo de narrativa peruana

RITA GNUTZMANN y, en relación con éste, el profesor y escritor fracasado León. En torno a don Manuel seguimos los pasos de su amante Tito (alias «Caradehumo») y su hijo Toño (llamado «HIJO DE MARICÓN» (p. 139). Las historias fragmentadas alternan en contrapunto sin un orden fijo y el tiempo se reduce a doce horas del 12 de octubre, día del Señor de los Milagros, en la década de los sesenta. La posición social separa claramente a los dos grupos: don Manuel practica la manipulación y ejerce el poder (económico, político, sexual y hasta jurídico) mientras que los Colmenares sufren la humillación, frustración y angustia, si bien tampoco ellos están libres de prejuicios sociales y raciales frente al serrano y a otros inferiores en la escala social y son amorales en su propósito de medro social, como Bety que piensa atar a un miraflorino mediante el sexo. La descripción de una de las fiestas en la casa de campo de Don Manuel muestra su poder y amoralidad, mientras que, en Lima, los estudiantes mueren bajo las balas de la policía:

sus íntimos, viejos femeninos, llegaron con sus jóvenes amantes al refugio de Santa Inés. En el almuerzo hubo langosta, ave, uvas de invierno traídas especialmente de Ica para su Tito goloso como ninguno, vino francés y habanos olorosos. [...] Don Manuel llevó a todos los íntimos con sus amantes en grupo ebrio, a galope de cadera suelta al aire, entre naranjos y olivos, al Nido Sevillano. (p. 37)

Al final, Miguel Colmenares se rebela contra la sociedad corrompida e injusta atacando la figura del Señor de los Milagros, acto por el que paga con su vida. Pero también el poderoso Don Manuel ha sido humillado y su casa destruida por su amante proletario Tito, dejando a su dueño sin fuerza vital. La sensación que brinda esta novela es la de un Perú «podrido» («jodido» para Zavalita en Conversación en la Catedral) y en crisis económica, moral y política, sensación reforzada en los fragmentos brevísimos que cierran el relato sin orden alguno (pp. 268 y ss.).

Con este texto, la novela peruana se abre a todas las innovaciones técnicas de los escritores anglosajones (Huxley, Joyce, Woolf, Faulkner, Dos Passos), como el contrapunto, el monólogo interior, la alternancia de puntos de vista, la yuxtaposición de fragmentos, innovaciones tipográficas (frases entre paréntesis, negritas para episodios del pasado y/o para monólogos interiores, flashbacks, simultaneidad temporal, etc.). Otro logro de la novela constituye el lenguaje de los personajes, diferenciado según la pertenencia a sus clases sociales: la «replana» (argot) para las pandillas, el estilo cursi y beato para doña María y sus radionovelas; el lenguaje pretencioso y calculador de Bety; la parodia del estilo periodístico; el lenguaje pornográfico de las pandillas en la procesión del Señor o el lenguaje oficial de Don Manuel, contrapuesto a sus pensamientos verdaderos...

Algunos críticos quieren incluir también en la «Generación del 50» a Julio Ramón Ribeyro $^{6}$ e incluso a Vargas Llosa, éste excluido de mi estudio, igual que José María Arguedas, puesto que ambos tuvieron una atención especial en otras dos ponencias. Efectivamente, Ribeyro prefiere, como aquella «generación», la brevedad del cuento frente a la novela (aunque es igualmente autor de tres novelas) y, en parte, se ocupa del tema de la difícil supervivencia de las clases desfavorecidas en la capital. Pero amplía el radio de sus preocupaciones a otros grupos y otros países, inducido por su estancia durante, aproximadamente, cuatro décadas en Europa, sobre todo en París, si bien es cierto que un único libro, Los cautivos (1972), tiene como escenario exclusivo a este continente. En alguno de sus textos teóricos, Ribeyro explica su enfoque del cuento como «una unidad de tiempo, lugar y acción» que evita «la dispersión del relato y logra [...] una especie de 'condensación dramática'», centrada en el momento "de una decisión humana» ${ }^{7}$. En cuanto al estilo, insiste en la simplicidad y la «expresión directa» (p. 47). En sus relatos limeños predominan los años 40 y 50, época de los mayores cambios estructurales de la ciudad y de problemas de hambre, miseria, violencia y falta de trabajo; la precariedad de la clase media; el racismo y el clasismo en todas sus variantes... Ribeyro explora tanto el mundo de los marginados (al igual que Reynoso y Congrains) como el de la clase media (los miraflorinos típicos que también pueblan los textos de Vargas Llosa y L. Loayza) y el decadente de la vieja «aristocracia» (como Bryce Echenique). Refleja, además, los cambios urbanísticos, por ejemplo la destrucción de la vieja Lima colonial en «Los eucaliptos» $\mathrm{y}$ «Tristes querellas en la vieja quinta» ${ }^{8}$. Sin embargo, a Ribeyro no le interesan los paisajes urbanos en sí sino los pequeños dramas (comedias o tragedias) de los personajes que los pueblan, dramas impulsados por diferen- 
cias de clases y razas (o, por el contrario, la comprensión más allá de las fronteras nacionales en «Los moribundos»), la ambición, el autoengaño, el amor, la envidia, etc. La mayoría de sus personajes son perdedores, algunas veces por las circunstancias socio-económicas y otras por desconocimiento de sus propias capacidades o por no distinguir entre fantasía y realidad, como el protagonista de «Explicaciones a un cabo de servicio».

Los dos cuentos más cercanos a la «Generación del 50» son «Los gallinazos sin plumas» (1954) y «Al pie del acantilado» (1959). El primero narra las penurias de los jóvenes Efraín y Enrique, explotados por su abuelo don Santos, quien les obliga a obtener comida del vertedero para su cerdo Pascual, aun cuando, pronto, los chicos caen enfermos. El sacrificio del perrito Pedro, único compañero de su infancia desolada, para servir de alimento al cerdo cada vez más voraz es el detonador de la tragedia: el hermano mayor Enrique empuja a su abuelo al chiquero, donde, indefenso por culpa de su pata de palo, será devorado por su propio cerdo. El futuro de los jóvenes hermanos tampoco parece prometedor, puesto que la «gigantesca mandíbula» de la feroz bestia urbana les espera al final. No existen relaciones humanas entre el abuelo y sus nietos por la dureza de éste, metafóricamente expresada por la pata de palo que refleja su mutilación interior. Mientras que don Santos «canta» a su «Pascualito», pega a los chicos por «haraganes», les «berrea» y los llama «pedazos de mugre». Don Santos, con nombre irónico, actúa como un inhumano empresario y su muerte en las fauces de su propio cerdo, simboliza al capitalismo que a menudo devora a los suyos.

La situación precaria se denuncia también en «Al pie del acantilado», que pertenece a Tres historias sublevantes, dedicadas a las tres regiones principales del Perú: costa, sierra y selva. El narrador de «Al pie...» es el propio protagonista Leandro quien ha sido desalojado de Lima con sus dos hijos para hacer sitio a la «modernización» y ha debido instalarse al pie del mencionado acantilado. En el fondo del barranco, en el lugar del antiguo balneario de Magdalena, ahora en ruinas, ellos construyen un nuevo hogar. El descenso social está simbolizado en este descenso geográfico lo mismo que la higuerilla que crece en el acantilado y se alimenta «de piedras y de basura» expresa metafóricamente la tenacidad de Leandro y la de otros marginados por salir adelante. La llegada de bañistas a este modesto lugar ofrece algunos ingresos, aunque con la muerte del hijo Pepe, quien se ahoga al arrancar los viejos hierros del mar para atraer a más turistas, Leandro sufre el primer revés y más tarde se sume en la soledad, puesto que su hijo Toribio prefiere retornar con su mujer a la ciudad, que lentamente extiende sus tentáculos hasta el acantilado. El nuevo plan de Leandro de sacar un dinerillo con la pesca se frustra al aparecer tres hombres representantes de la voraz ciudad. Son agentes municipales que reclaman el acantilado y sus playas para construir un nuevo establecimiento de baños. El narrador, «a la deriva» y «cansado de la vida, [...] cansado de todo» (p. 225), encuentra en el último momento una nueva higuerilla. En contra del cacareado pesimismo de su autor ${ }^{9}$, ésta simboliza un nuevo comienzo, todo lo precario que se quiera, a la vez que muestra la fortaleza de los pobres para valerse ellos mismos en momentos en que las instituciones sociales y políticas no sólo no funcionan sino que se convierten en enemigos de su frágil supervivencia.

Pero los cuentos de Ribeyro en absoluto se limitan a la reivindicación social; incluyen lo fantástico, la nostálgica reconstrucción autobiográfica y los grandes temas existenciales como la soledad (del judío errante Monsieur Baruch), el amor («Silvio en el rosedal»), la ilusión frustrada (la quimera del amor y la juventud del otoñal Huamán en «La juventud en la otra ribera»), la vida y la muerte (el aprendizaje tardío y peligroso del mismo Huamán), etc. Dos buenos ejemplos de cuento fantástico son «Los jacarandás» (1970) y «Doblaje» (1955), que juegan con el mismo nombre (Winnie) de la mujer y están centrados en el tema del doble, favorito de los románticos y también frecuentado por Borges y Cortázar con excelentes resultados. «Doblaje» gira en torno a un joven pintor londinense que busca su doble en Australia, donde se enamora de una mujer, Winnie, para rechazarla más tarde al sospechar que ella ya estuvo en la nueva casa con otro hombre. Al retornar a Londres no sólo su último cuadro inacabado ha sido terminado sino también un hombre idéntico a él acudió a su club de siempre.

Son claramente autobiográficos los cuentos de Sólo para fumadores (1982) y Relatos santacrucinos (1992), dedicados al barrio

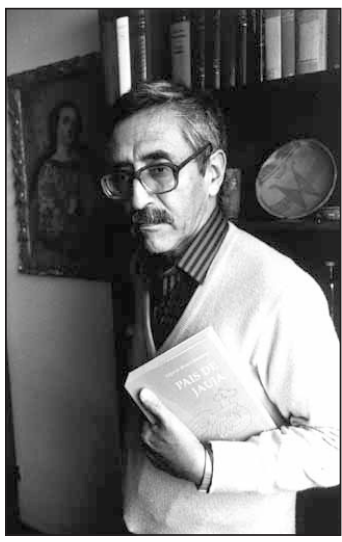

Edgardo Ribera.

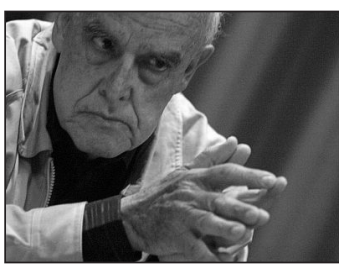

Enrique Congrains Martín.

9

En su diario lop. cit., 1995 vol. III, p. 248), Ribeyro da una definición del pesimista a la que él mismo se adhiere: "Se puede ser pesimista, pero henchido de esperanza».

Una retrospectiva sobre medio siglo de narrativa peruana RITA GNUTZMANN 
10

La tentación, 1993, vol. II, pp. 219-220.

11

Julio Ortega, "Los cuentos de Ribeyro», Cuadernos Hispanoamericanos, 417 (1985), p. 134.

12

También el crítico P. Elmore, El perfil de la palabra. La obra de Julio Ramón Ribeyro, ve en el misterioso hombre una parábola del artista y "con el paso de los años el pequeño escolar también se entregará al oficio de contar historias». Lima, PUCP/FCE, 2002 , p. 102.

13

James Higgins, Cambio social y constantes humanas. La narrativa corta de Ribeyro, Lima, PUCP, 1991, p. 163.

14

Op. cit., p. 214.

15

Giovanna Minardi, La cuentística de Julio Ramón Ribeyro, Lima, Banco Central de Reserva del Perú, 2002, pp.187-188.

16

Ibid., p. 190.

17

La tentación, 1993, vol. II, pp. 216-217

18

Alfredo Bryce Echenique, Un mundo para Julius, Lima, Mosca Azul, 1980.

19

Bryce ensaya otra historia muy distinta con los mismos elementos en el cuento "jAl agua patos!» de La felicidad ja, ja (1974) en torno a la decadencia de otra (¿̀la misma?) familia limeña y el doloroso episodio de la muerte de un patito que se sobrepone a la de la hermana Rafaela en Boston, a la cual ya había sustituido por una vecinita hace tiempo. Cf. Wolfgang Luchting, Alfredo Bryce/Humores y malhumores, Lima, Milla Batres, 1975, p. 85.

Una retrospectiva sobre medio siglo de narrativa peruan

RITA GNUTZMANN miraflorino de su infancia y adolescencia, cuando Lima aún era «una ciudad limpia y apacible [...] rodeada de huertos y cultivos» (p. 681). Pero también otros relatos son clasificados por el propio autor como «autobiográficos»10, por ejemplo, «Por las azoteas», «El polvo del saber», «El ropero, los viejos y la muerte», «Los eucaliptos» y "Página de un diario». En el primero, un niño de diez años descubre en las vacaciones de verano el mundo de las azoteas, «recinto aéreo» o mundo de la libertad en oposición al «mundo de los bajos» que habitan los adultos, «atroz mundo, donde todo era obediencia» (Cuentos, p. 163). Pero no sólo dominan el desorden y los desechos en el mundo de arriba sino también lo desconocido y la literatura («un espacio imaginario» como lo llama J. Ortega $)^{11}$ en la persona del misterioso hombre de la perezosa que le cuenta historias y le regala un (su) libro. Será la herencia de aquel desconocido, marcado por la muerte, que años más tarde permite al hombre mayor evocar en primera persona aquellos momentos de aprendizaje de la vida $y$ del arte de narrar y fantasear ${ }^{12}$.

La preocupación por los grandes temas existenciales como la soledad y la muerte o el amor están presentes en: «Nada que hacer, Monsieur Baruch» (1967) y «Silvio en El Rosedal» (1976). Sírvanos brevemente el último para ver su tratamiento del amor. El joven Silvio hereda la finca El Rosedal y, atraído por su belleza, decide instalarse definitivamente en ella. Pronto descubre un extraño dibujo en el rosedal, parecido a la palabra RES. Perplejo busca diversos significados (en latín «cosa», en catalán «nada») o leerlo como palíndromo SER, el cual lo instiga a realizarse («ser») en la música y retomar la práctica del violín. Transcurridos aproximadamente diez años, aparece la joven sobrina Roxana Elena Settembrini y Silvio, rendido ante la belleza de la quinceañera, cree haber encontrado por fin la solución al enigma ya que las iniciales de la joven coinciden con la palabra de su jardín. Sin embargo, en una fiesta, Silvio descubre que Roxana sólo se fija en el hijo del hacendado más rico. Subido al minarete de su jardín entiende que en éste «no había enigma ni misiva» y «empezó a tocar [el violín] para nadie [...]. Y tuvo la certeza de que nunca lo había hecho mejor» (Cuentos, p. 502). Queda al lector la labor de descifrar la simbología del cuento. Para J. Higgins ${ }^{13}$, el jardín es «un símbolo de la ineluctable incomprensibilidad del mundo». Para P. Elmore, Silvio renuncia a la idea de que «su vida esté sujeta [...] a un plan concebido por un Autor trascendente» ${ }^{14}$. En una entrevista con G. Minardi, Ribeyro comenta que en el cuento quiso expresar sus «ideas sobre la realidad, sobre la vida» ${ }^{15}$. Coincide con la busca del autor «de serenidad, de conocimiento de sí mismo, de felicidad gracias a una ascesis» ${ }^{16}$. Aunque el tema del hombre mayor, enamorado de una quinceañera, es tratado con una ironía sutil, Silvio merece comprensión por su anhelo artístico, su rechazo del mundo basado en el dinero y el status y por su afán de conocimiento.

Es cierto que Ribeyro no ha introducido en sus relatos innovaciones técnicas sino que le inspiraba «una aprehensión inédita de la realidad ${ }^{17}$, como bien muestra el texto que se acaba de mencionar. Su estilo es sutil y culto y cada vez más parco en lo que a discurso directo se refiere, en el que, por otro lado, nunca intenta remedar los lenguajes orales socioculturales, ni siquiera en los relatos autodiegéticos como «Al pie del acantilado». Domina el arte de sugerir y de crear determinadas atmósferas y, sobre todo, el empleo acertado del símbolo para mostrar las significaciones y relaciones secretas, como la higuerilla en $« \mathrm{Al}$ pie del acantilado», el rosedal en «Silvio...», el espacio «aéreo» en «Por las azoteas», la «hora celeste» en «Los gallinazos sin plumas»...

Uno de los autores peruanos más conocidos en España, junto a Vargas Llosa, es sin duda Alfredo Bryce Echenique; saltó a la fama con su novela $U n$ mundo para Julius ${ }^{18}$ que aún hoy es considerada su obra maestra. Entra dentro del subgénero del Bildungsroman (novela de aprendizaje), aunque sólo abarca la infancia de Julius entre los cinco y once años. Tempranamente huérfano de padre crece en el ambiente superficial de la oligarquía limeña, con un padrastro ricachón y mujeriego y una madre frívola, aparte de los hermanos mayores Santiago y Bobby, productos de su clase. Sólo la hermana Cinthia comprende al niño ${ }^{19}$, pero su muerte en la lejana Boston lo deja al cuidado de la servidumbre, sobre todo de su ama Vilma. Los criados provienen de las tres regiones del Perú y representan las diferentes mezclas raciales: el ama chola de Puquio, Vilma; la cocinera selvática Nilda; el chófer limeño y zambo Carlos y el serrano Celso; con ellos el niño hace su primer aprendizaje social y racial. El colegio y la piscina del Club exclusivos completan su formación infantil 
que termina de manera traumática al enterarse de que su querida ama Vilma se ha convertido en prostituta después de haber sido expulsada por su familia por culpa del hermano Santiago quien la violó y de que su otro hermano Bobby acaba de usar su servicio sexual. Termina la novela con Julius llorando silenciosamente ante el «vacío grande, hondo, oscuro» que le espera a partir de ahora. De esta forma, dos momentos traumáticos enmarcan la historia de Julius: la pérdida del padre al comienzo y la de la inocencia (la infancia) al final.

El mundo de Julius está dividido en dos grupos: la de la familia oligárquica y la de los sirvientes; el niño no se integra ni en uno ni en otro: «de espaldas» con respecto a su familia, tampoco pertenece al ambiente de la servidumbre como muestra el episodio de la lavandera Arminda, de cuya casa huye vomitando, aunque más tarde compensa aquella afrenta sacando el ataúd de la pobre lavandera por la puerta grande del nuevo palacio familiar. En el mundo de esta clase dominan «valores» como el dinero, el éxito, el machismo (para los hombres) y la belleza, la elegancia y el lujo (para las mujeres). Por su carácter diferente, el padrastro considera a Julius un «cojudo», «chupa cirios» e «imbécil» y prefiere a sus hermanos vividores y «viriles». La madre de Julius, Susan-«linda» y el padrastro Juan Lucas son duplicados (y completamente ridiculizados) en los advenedizos Juan Lastarria y su mujer, Susana-«fea»; a estos se añaden los de Altamira (decadentes y germanófilos), periodistas, algún historiador, los norteamericanos (Lester Lang III y IV) y los amigos de Bobby para completar la fauna adinerada.

La servidumbre del viejo palacio se distingue por su cariño y fidelidad hacia la familia de Julius; pero con Juan Lucas, todavía hacendado pero ya metido en el mundo moderno de los negocios, se abandona el viejo sistema patriarcal y se sustituye a los viejos por nuevos criados, más egoístas y mandones como «la Decidida» o preocupados por su promoción y que son capaces de cambiar de dueño o profesión, como Imelda; su domicilio está alejado del palacio de Julius; viven en barrios como La Florida (Arminda), ejercen en La Victoria (Vilma) o deben volver a la selva de donde habían venido (Nilda). El relato, al parecer en torno a un individuo y su desarrollo, muestra a las claras los grandes cambios experimentados por el Perú y, sobre todo por su capital, a fines de los años 40 y comienzos de los 5020: nuevo capitalismo, nuevas relaciones sociales, migración del campo a la ciudad, surgimiento de las barriadas, abandono del centro por la clase alta y su establecimiento en barrios exclusivos como Monterrico, el surgimiento de la nueva clase media profesional (periodistas como el «Gargajo» López, el historiador gordo y homosexual, el arquitecto de moda) y la presencia del capital norteamericano.

Los logros más llamativos de esta primera novela (antes, Bryce había publicado los cuentos Huerto cerrado) son el estilo, el multiperspectivismo y la pluralidad de voces. $\mathrm{Si}$ en la frase que abre el relato parece tratarse de un narrador omnisciente («Julius nació en un palacio...»), en seguida se entromete una frase en estilo directo «[la carroza] usó tu bisabuelo, Julius [...] no la toques», prohibición pronunciada por la madre en algún momento no concretado, puesto que la descripción que sigue reza: «y él, de espaldas a su mamá [...] tratando de alcanzar la manija de la puerta» (op.cit., p. 9). La forma cariñosa «su mamá» (aunque en tercera persona del posesivo) deja claro que la perspectiva se ajusta a la del protagonista, aunque él no sea el narrador (la diferencia genettiana entre quien narra y quien ve; cf. los recuadros en E. Snauwaert ${ }^{21}$. La focalización cambia constantemente, pasando del narrador a un personaje y de éste a otro o de un discurso directo a pensamientos del mismo personaje que delatan la falsedad de las palabras pronunciadas. Estos cambios de perspectiva se indican mediante los cambios del tiempo («venía a buscarlo una muchacha, una que su mamá [...] decía hermosa la chola, debe descender de algún indio noble», $U n$ mundo..., p. 10), introducción de adverbios temporales y deícticos espaciales («esta» en vez de «aquella»), exclamaciones, imperativos («no la toques»), denominaciones particulares y nombres cariñosos según el hablante (el «darling» estereotipado de Susan; «Lolo, Lolín, Lololo» de la profesora de castellano); palabrotas y aumentativos («cojudo, coctelazo», típicos de Juan Lucas), adjetivos de enjuiciamiento (nada mejor que el hilarante episodio de Juan Lucas como acólito con sus calificaciones «horrible, inmundo, asqueroso, sucio, espantoso» para los demás feligreses, p. 125), diminutivos o aumentativos (el «buenísimo» del ingenuo niño), anacolutos...

El resultado es un discurso híbrido, mezcla de diégesis y diálogo y diferentes perspectivas. Gracias a la corta edad de Julius, se

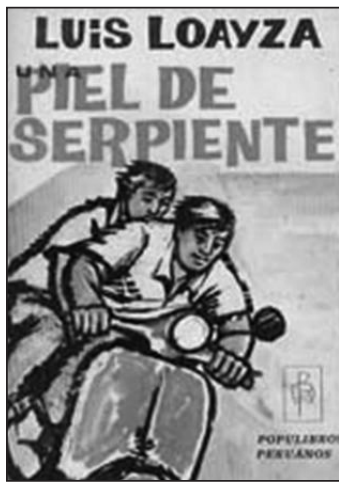

20

Existen fechas concretas como 1937 (Susan se enamora de su primer marido), la presidencia de Eisenhower (de 1953-1961, op.cit. p. 115) y la (segunda) de Batista en Cuba (1952-1959, ibid., p. 331).

21

Erwin Snauwaert, Crónica de una escritura inocente. La focalización implícita como base interpretativa de las novelas de Alfredo Bryce Echenique, Leuven, Leuven UP, 1998, pp. 19,26

Una retrospectiva sobre medio siglo de narrativa peruana

RITA GNUTZMANN 
Julio Ortega, «Introducción» a A. Bryce Echenique, Un mundo para Julius, Madrid, Cátedra, 1993.

23

Isaac Goldemberg, La vida a plazos de don Jacobo Lerner Lima, Libre.1, 1978.

24

Gregorio Martínez, Canto de sirena, Lima, Mosca Azul, 1977.

\section{5}

Kam Wen Siu, La vida no es una tómbola, Morrisville/NC, Abajo El Puente, 2008.

Una retrospectiva sobre medio siglo de narrativa peruana RITA GNUTZMANN crean momentos de ambigüedad, crítica indirecta o abierta hilaridad como en el episodio de Ranchal-padre que llega en un automóvil «increíble», «Sí, como en las películas de gansters», y que es (y no parece ser) $\mathrm{Al}$ Capone, con voz «mala» y mirada «terrible» (p. 262). La novela, además, se caracteriza por el tono coloquial, espontáneo y lleno de digresiones que irán en aumento en novelas posteriores, sobre todo en La vida exagerada de Martín Romaña (1981), un verdadero «gusto» por la redundancia y la proliferación (W. Luchting, p. 86). Al contrario de Ribeyro que busca un estilo neutro, Bryce pretende dar la sensación de estilo oral, imitar la «quintaesencia del habla de Lima» que encontraba en su amigo, el Gordo (Alberto) Massa, al que imaginaba como interlocutor de su relato (pp. 85,105). Esta (fingida) oralidad y, unidos a ella, la proliferación, la digresión y el humor constituirán, con los años, los rasgos inconfundibles de su estilo. Aparte de este "tonito Bryce», Julius (el relato y el personaje) anticipa características que se volverán a encontrar en otros protagonistas como Manongo Sterne (guiño al autor de $A$ Sentimental Journey) de No me esperen en abril (1995): son héroes individualistas, sentimentales y solitarios, de una exagerada sensibilidad; buenos observadores de la sociedad, rechazan su materialismo y machismo (aunque Manongo se haga un tiburón corrupto de las finanzas) y exaltan determinados valores como el amor, la amistad y la lealtad. Incluso la vocación literaria de estos protagonistas se puede ya detectar en la composición escolar de Julius «El señor de negro» (Un mundo, p. 269) dedicada al padre de su enemigo Fernandito Ranchal, una venganza más refinada que un puñetazo infantil. La mayoría de los protagonistas son relatores de su propia historia (se trataría de «biografías imaginarias» en palabras de J. Ortega ${ }^{22}$; tanto Pedro Balbuena (Tantas veces Pedro), como Martín Romaña, Felipe Carrillo y Max Gutiérrez (Reo de nocturnidad) compensan sus fracasos diarios al evocar sus vidas con humor y nostalgia.

En los años 70 se publican algunas novelas que comprueban la multiculturalidad y multietnicidad del Perú, más allá de la reconocida «heterogeneidad» (Antonio Cornejo Polar), aplicada a la población indígena. Por ejemplo, Isaac Goldemberg, de ascendencia judía, publica en 1978 La vida a plazos de Don Jacobo Lerner $^{23}$ (original en inglés) sobre las duras experiencias de un inmigrante judío ruso (ukraniano) en Perú. No sólo se encuentra con el rechazo de los peruanos sino, igualmente, con la incomprensión y el desprecio de su propia comunidad. Una variedad de voces y documentos aportan fragmentos sobre la vida del personaje y la de otros inmigrantes judíos como Daniel Abromovitz (quien se suicida), León Mitrani (perdido), las mujeres Miriam y Sara o Samuel Edelman («hombre noble»), el único que se arraiga en el país adoptivo. La población negra está representada en los relatos de Gregorio Martínez (y, antes, en los de Antonio Gálvez Ronceros). En Canto de sirena (1977)24 Martínez pone en boca del octogenario negro Candelario (Candico) Navarro el relato de su vida, cercano a las «novelas de testimonio» que también frecuentaban autores como Miguel Barnet en Cuba y Elena Poniatowska en México. El protagonista no sigue ninguna cronología desde su nacimiento en 1895 hasta el momento de fijar sus memorias en 1976. Nos enteramos de su época de trabajador con los Denegri y como «huaquero» con el arqueólogo (real) Tello, sus faenas en las tierras de un ministro y su regreso a Coyungo (en Nazca), de donde era oriundo. Martínez subraya sobre todo el saber (y sabor) del hombre cercano a la tierra y la naturaleza, con gustos culinarios y eróticos definidos. Tampoco se olvida de la lucha por los derechos de igualdad de su raza y de mostrar el habla popular del personaje. Una década más tarde, en 1985, Siu Kam Wen se ocupa de los inmigrantes chinos en los cuentos El tramo final, sobre todo de los descendientes de éstos en segunda generación como Héctor de «El deterioro», quien será también protagonista de la reciente novela de Siu, $\mathrm{La}$ vida no es una tómbola (2008) ${ }^{25}$. Vive explotado por su padre en la tienda de abarrotes y conoce la violencia, el racismo y el desprecio contra su comunidad y los selváticos en el colegio nocturno Bentín. La problemática de la identidad cultural, lingüística y social de la comunidad china conoce variaciones en otros personajes como la bella y frustrada Maggie, el tío artista Elías, el criminal Hermanito $\mathrm{Ca}$ ñón, etc. Maggie lo expresa a las claras: no se identifica «ni con los peruanos ni con los chinos» y toda su vida será «una exiliada doble» (op. cit., p. 109).

En la década de los 90 llamaron la atención tres novelas sobre el problemático mestizaje del Perú: La violencia del tiempo (1991) de 
Miguel Gutiérrez, País de Janja (1993) de Edgardo Rivera Martínez y Ximena de dos caminos (1994) de Laura Riesco. Gutiérrez y Rivera Martínez se sitúan en las antípodas al enfocar el tema: el primero hace hincapié en las desigualdades e injusticias; el segundo subraya el logrado equilibrio en la sociedad mestiza de Jauja. La novela de Riesco muestra, por su parte, las diferencias sociales y raciales, pero pretende superarlas mediante la fantasía y la creación.

La violencia del tiempo ${ }^{26}$, un inmenso fresco de más de mil páginas, se centra en la familia piurana de los Villar, que se origina en el desertor español Miguel Villar de los tiempos de la independencia, y la indígena violada, Sacramento Chira. La humillación del bisabuelo por el terrateniente regional es el origen del odio de los descendientes mestizos obsesionados con su «linaje». Esta «herida inicial», causada por los azotes públicos de Cruz Villar a manos del blanco Benalcázar, es el recordatorio de su inferioridad social y racial, y provoca «pasiones, homicidios, venganzas» (vol. I, pp. 15, 36). Como en la célebre saga de García Márquez, se trata de varias (aquí cinco) generaciones que sirven de paradigma para la población mestiza, provinciana y marginal del Perú «los comemierda del mundo» (p. 222), y sus sufrimientos, a la vez que se denuncia su propia violencia, machismo y prejuicios raciales, como el mismo Cruz que no pedía amor a su familia sino «sometimiento total a su potestad». Cruz también es machista al fundar dos familias paralelas con dos hermanas aindiadas, Trinidad y Lucero, a la vez que desprecia a los indios como «hembras por naturaleza condenadas [...] para ser violadas por el macho» (vol. II, p. 138) y es él quien vende su hija Primorosa al blanco Benalcázar. No en vano el «cronista» Martín, último descendiente de los Villar, que se niega a tener hijos, cita la conocida frase de Stephen Dedalus: «La historia es una pesadilla de la cual quisiera despertar» (vol. I, p. 133).

País de Janja, por el contrario, sugiere un mestizaje sin conflictos entre el mundo occidental y el andino, entre la cultura clásica y la tradicional peruana ${ }^{27}$. El tema se plantea como relato de aprendizaje del joven Claudio Alaya en la pequeña ciudad de los Andes centrales durante las vacaciones estivales de 1946/1947. Rivera se basa en los hechos reales de que Jauja nunca sufrió el latifundismo y que sus habitantes son pequeños agricultores, artesa- nos y profesionales con un nivel educativo y cultural por encima de otras regiones. A ello se agrega su apertura al mundo gracias a su atracción como centro de salud internacional para tuberculosos. La familia Alaya, aunque modesta, ostenta una amplia cultura que incluye la tradición clásica y la popular-andina; el quinceañero Claudio domina las partituras de Bach, Beethoven y Mozart igual que transcribe los yaravies, buaynos y pasacalles andinos con la ayuda de la madre; lee, por instigación de su hermano bibliotecario, la Iliada y los poemas de Vallejo y Eielson; pero, paralelamente, la criada chola le cuenta de amarus, ríos de aguas oscuras y la flor sullawayta; Claudio se siente atraído por la misteriosa Elena Oyanguren, nueva Helena de Troya, y hace el amor con la odalisca Zoraida pero ama a la niña chola Leonor; las muy andinas tíasabuelas y hermanas Heros repiten un amor incestuoso de los tiempos griegos y entierran al hermano-amante, como Antígona, contra la voluntad del padre... Otros personajes, como el fabricante de ataúdes Fox Caro, el «Caronte» Mitrídates o el rumano Radulescu, aportan cosmopolitismo a la vez que participan en la vida de la pequeña ciudad andina. En fin, un verdadero himno a la armonía de lo propio y lo internacional, un modelo de convivencia pacífica y tolerancia, sorprendente en el momento en que fue escrito.

Parecido en su intento de plasmar la vida en un pueblo andino pero menos idílico por los claros choques sociales resulta Ximena de dos caminos $^{28}$. Igual que en la novela de Rivera Martínez se trata de un aprendizaje, en este caso de una niña de unos cuatro o cinco años en un pueblo innombrado de la sierra, claramente identificable con La Oroya, donde el padre de la autora trabajaba para la compañía minera norteamericana Cerro de Pasco Corporation, objeto de denuncia en la pentalogía de Manuel Scorza, La guerra silenciosa. Abarca unos quince meses de los también años cuarenta, cerca del final de la II Guerra mundial (pp. 28, 36, 43). En este tiempo, Ximena hace varios aprendizajes: el socio-cultural dentro y fuera de la familia y otro personal, el de la escritura, un punto este en que coincide con el Claudio riverano. El padre no sólo le enseña las primeras letras y las mitologías clásicas o cosas prácticas como saltar acequias, sino también llama la atención sobre las desigualdades sociales que reinan aún en el campo: critica el comportamiento de
26

Miguel Gutiérrez, La violencia del tiempo, 2 vols., Lima, Milla Batres, 1992.

27

Edgardo Rivera Martínez, País de Jauja, Lima, Peisa, 1994. El autor pone como epígrafe la cita de un ensayo arguediano que caracteriza el valle de Jauja como ejemplo de «integración ex cepcional de razas, de culturas y de sistemas económicos».

28

Laura Riesco, Ximena de dos caminos, Lima, Peisa, 1994.

Una retrospectiva sobre medio siglo de narrativa peruana

RITA GNUTZMANN 
29

Dice Zein Zorrilla en «La novela andina»: "desde finales de los años setenta [...] la Novela Andina muda de temas y tramas, de personajes y escenarios. La devastación de la gran sociedad feudal es el gran tema, la migración y la búsqueda de un nuevo orden [...] Los temas de la novela andina contemporánea, no son más los temas de la novela indigenista. Andino no es más sinónimo de Indigenista». Revista peruana de literatura 2005, www.pasacalle.net.

30

El término, derivado del griego anomos (sin ley), fue introducido en la sociología por E. Durkheim y significa "ausencia de normas - valores sociales aceptables» con referencia tanto al individuo como a la sociedad en general.

31

Fernando Ampuero, Cuentos escogidos, Lima, Alfaguara, 1998, y Caramelo verde, Lima, Jaime Campodónico, 1992.

Una retrospectiva sobre medio siglo de narrativa peruana

RITA GNUTZMANN la clase alta peruana para con sus trabajadores y peones (ejemplarizada en la arrogante prima Casilda que llama «propios» a los empleados (p. 43). Aunque la madre de Ximena pertenece a este mundo (es la guardiana del pasado familiar mediante su álbum de fotos), es también la que introduce a la hija en el mundo de la fantasía y los cuentos de hadas y hace de enlace con el mundo quechua del Ama Grande. Son sobre todo el primer y el último capítulo los que se ocupan del aprendizaje social y racial de Ximena; el primero muestra a la mimada y egoísta niña defendiendo sus peluches americanos contra el paupérrimo chico indio que quisiera tocarlos. En el último, Ximena observa el maltrato que se inflige a los mineros indios en huelga, quienes, al estilo de la novela indigenista, son represaliados por los militares. La historia de la familia del pequeño Pablo recuerda igualmente los relatos indigenistas, con la expulsión de los campesinos de sus tierras por un terrateniente codicioso y el maltrato y la miseria de los obreros indios en las minas. Aunque Ximena, como hija de un empleado de la misma compañía explotadora y bisnieta de un terrateniente expoliador, se siente culpable, no es capaz de defender al joven minero acusado injustamente de secuestrarla.

Como se dijo anteriormente, otro objetivo de la autora es el cultural. La novela incluye una gran variedad de textos culturales y literarios, mezclando, como en la novela de Rivera Martínez, el mundo occidental y el andino, el clásico y el popular, lo racional y lo mágico, la escritura y la oralidad. Frente al mundo occidental de los padres (popular el de la madre con sus cuentos de hadas, brujas y princesas $y$ racional el del padre y su enciclopedia), el Ama Grande introduce a Ximena en el mundo de la magia andina, con culebras que conocen el futuro y el pasado, cóndores y pumas sobrenaturales, huacas y árboles, aunque ella como india creyente cuenta igualmente historias bíblicas y de santos. También Pablo, el niño minero indio, puede comunicar con la blanca Ximena gracias a sus dotes de narrador de cuentos mágico-míticos; conjura el peligro del asalto militar mediante sus cuentos, que incluyen el mito del Inkarrí recopilado por J. M. Arguedas. Aunque narrado en tercera persona, la perspectiva está cerca de la protagonista y el último capítulo no deja ninguna duda de que en realidad estamos leyendo los recuerdos de ésta años más tarde, después de haberse convertido en aquella visitante misteriosa que le interroga sobre lo que ocurrió en aquel campamento minero y le obliga a fijar por escrito aquel episodio traumático (p. 222).

La reivindicación por Riesco y Rivera Martínez del mundo andino, pero no desde lo rural-indígena sino desde una clase media urbana culta, conocedora del mundo quechua y el cuidadoso empleo en sus relatos de técnicas literarias modernas y con una obvia preocupación lingüística y estilística, les acerca a lo que escritores como Luis Nieto Degregori, Zein Zorrilla y Enrique Rosas Paravicini proclaman como la nueva «narrativa andina» ${ }^{29}$.

Pero ya desde los años 80 habían surgido textos (primero cuentos breves), que se preocupaban de la situación creada en el país con el surgimiento de Sendero Luminoso, situación que pronto se degradó en una guerra de exterminio entre este grupo y el ejército, encargado de restablecer la seguridad tanto por el presidente Belaúnde como por Alan García (1980-1985; 1985-1990), que dejó un saldó de más de 70.000 muertos, la mayoría de ellos campesinos quechuaparlantes de las zonas andinas. Tampoco Lima se salvó de apagones, atentados, coches bombas y masacres, un estado de «anomia» según los sociólogos ${ }^{30}$. Más tarde, en los años 90, el gobierno de Fujimori, con su corrupción rampante y la subordinación de las instituciones al poder personal del presidente y su Rasputín, Montesinos, su autogolpe en 1992, los asesinatos selectivos de Barrios Altos y la Cantuta (1991 y 1992), el exterminio de los secuestradores del MRTA (Movimiento Revolucionario Túpac Amaru) en la Embajada Japonesa (1997) continuaron el estado de anormalidad, a pesar de que ya en 1992 había sido capturado el líder senderista Abimael Guzmán.

Naturalmente los intelectuales no podían quedarse alejados de lo que ocurría y fueron sobre todo los escritores y la gente del cine quienes pronto reflejaron su preocupación en relatos y películas. Aunque tal vez Fernando Ampuero $^{31}$ no fuera el primero, su cuento kafkiano «El departamento» convence aún hoy con su tono objetivo para retratar una situación absurda, en la que un inocente vendedor de coches es detenido y liberado cuatro veces tras largos interrogatorios por el simple hecho de haber alquilado un apartamento ocupado antes por un «subversivo». Naturalmente no sobrevivirá a la quinta detención, la misma 
noche que los subversivos vuelan una torre de alta tensión. No menos excepcional resulta su «Taxi Driver sin Robert de Niro», retrato de comienzos de los 90, puesto en boca del mismo personaje forzado por el paro a ejercer de taxista que se gana un dinero extra robando y vendiendo a borrachos. La perplejidad del propio personaje se prolonga en la del lector, aliviado por un humor sutil.

A menudo el género policial y negro sirve para retratar el país, como lo hace el mismo Ampuero en Caramelo verde (1992, con un epígrafe de D. Hammett) que denuncia los años de hiperinflación y empobrecimiento de Alan García, con una Lima «informal» de cambistas, vendedores ambulantes, mendigos, huelguistas, matones, prostitutas, senderistas, blanqueadores de dinero, policías corruptos y negocios donde comprar todo tipo de armas, ametralladoras incluidas. Otro especialista en el género policial es Alonso Cueto, sobre todo con Grandes miradas (2003) y La hora azul (2005) ${ }^{32}$; la primera revela la podredumbre de los años de Fujimori-Montesinos; el asesinato del juez honesto, Guido Paz (basado en un hecho real) convierte a su novia en ángel vengador y asesina ella misma. Una cita sobre el funcionamiento de las bandas de matones, autoproclamados «médicos», da el ambiente de la época: «operan» metiendo el cuchillo «en la barriga y después jalar arriba y abrir rico» (p. 42). En la segunda, un abogado acomodado se convierte en detective para rastrear la vida criminal de su padre, el Comandante Ormache, que torturó, violó y ejecutó a sus víctimas en el cuartel so pretexto de que eran terroristas. Por encima del tratamiento policial, los relatos de Cueto siempre bucean en la psicología de los protagonistas y su capacidad para la violencia y el crimen. El más importante director de cine peruano, Francisco Lombardi, filmó la novela bajo el título Mariposa negra (guión de la poeta Giovanna Pollarollo), con importantes cambios, como la eliminación del locutor Javier y la ampliación del papel de la periodista Angela, que hereda el cinismo del locutor, aparte del final que convierte a la protagonista en una más de los miles de «desaparecidos».

También el relato histórico fue una forma de reflexionar sobre la violencia; autores como José Antonio Bravo, Luis Nieto Degregori, Oscar Colchado Lucio, Fietta Jarque y Sandro Bossio evocan episodios del pasado para explicar o buscar antecedentes y paralelos con el presente. Como en la llamada «nueva novela histórica», se suele tratar de personajes marginados por su raza (india o negra), su religión (judía) su sexo o profesión (mujeres y prostitutas), su aspecto físico (desfigurado) o su carácter (contestatario e intelectual). Los momentos elegidos son los de extrema violencia, como el exterminio de los últimos resistentes de Vilcabamba por el virrey Toledo, la Inquisición, el levantamiento de Tupac Amaru y Atusparia, las sublevaciones de esclavos negros, etc. El llanto en las tinieblas de Bossio (2002) ${ }^{33}$ es un excelente ejemplo. Si a primera vista cuenta el amor con final trágico entre el músico desfigurado Balmes y la prostituta Ligia María, la historia profunda denuncia el fanatismo y las persecuciones de la Inquisición en tiempos de la Ilustración. Las catástrofes naturales como terremotos y la peste contribuyen igualmente a acentuar el ambiente de terror. El mejor amigo, el inocente médico Bisbal, sucumbe a las nuevas máquinas importadas para la tortura, porque ni la inocencia ni el hecho de no ser «blasfemo, ni hechicero, ni judío, ni luterano» ofrecen la garantía de escapar a las garras de la Inquisición (p. 28). No sólo son proscritas las grandes obras del humanismo y la teoría heliocéntrica de Galilei, también las mujeres sufren el estigma de ser consideradas inferiores y a los negros se les niega la posibilidad de tener alma. Bossio no sólo critica el oscurantismo, la intolerancia y la violencia del siglo XVIII (el «Siglo de las Luces») sino que nos hace pensar inevitablemente en el parecido ambiente apocalíptico de «la década de la violencia» con su guerra interna y una epidemia de cólera, aparte de la mencionada hiperinflación.

Para no alargar más, termino con un tema muy frecuente en estos años, tanto en los relatos como en el cine: el exterminio de toda una comunidad a manos de los militares. Félix Huamán Cabrera tuvo un éxito inaudito (aunque casi secreto) con Candela quema luceros (1989) ${ }^{34}$, aún inédita y desconocida en España y Europa. El origen de la masacre de los yawarhuaitinos es la secular incomprensión lingüística y cultural entre el indígena y el blanco. Los comuneros acusan a un abigeo del asesinato de la virgen de su pueblo; cuando las autoridades blancas comprueban que no se trata de una mujer viva sino del culto a una estatua sagrada sueltan al «criminal» e insultan a los indígenas por su ignorancia.
Alfonso Cueto, Grandes miradas, Barcelona, Anagrama 2005 y La hora azul, Barcelona, Anagrama, 2005 (Premio Herralde). También el reciente Premio Alfaguara, Santiago Roncagliolo, usa el patrón en Abril rojo (2006).

33

Sandro Bossio, El llanto en las tinieblas, Huancayo, Industria Gráfica Obregón, 2005.

34

Félix Huamán Cabrera, Candela quema luceros, Lima, Ed. San Marcos, 2003

Una retrospectiva sobre medio siglo de narrativa peruana

RITA GNUTZMANN 
Cf. Comisión de la Verdad y Reconciliación, Informe final, 2003, vol. IV, p. 34 (www.cverdad.org.pe).

36

Cf. Ángel Fernández-Santos, "Una película polémica. La boca del lobo», El País, 2-1-1989.
Estos pretenden aplicar su propia ley, por lo que sus dirigentes son encarcelados y más tarde liberados por la comunidad, acto que sirve de pretexto para un «escarmiento» por parte del ejército. El único superviviente es el narrador Cirilo que evoca la masacre y los muertos, quienes le responden desde ultratumba. Probablemente muchos recordarán la película del mencionado Lombardi, $\mathrm{La}$ boca del lobo (1988), igualmente sobre un guión de la poeta Pollarollo. En la película la violencia no es fruto de un malentendido, sino del desprecio y la prepotencia de los militares (especialmente Quique y el Teniente Roca) al violar a una joven indígena, golpear a muerte a un comunero y acusar falsamente a los convidados de una boda de ser senderistas. No se usa, como en Candela, la voz dolorida de un comunero como relator, pero la mirada escrutadora de la niña al comienzo $\mathrm{y}$ al final hace el mismo papel. Tal vez el éxito de la película no se deba tanto al hecho de haberse basado en acontecimientos reales (el fusilamiento de la comunidad de Socos ${ }^{35} \mathrm{si}^{-}$ no a haber usado la estructura de «los viejos Westerns de patrullaje militar en un territorio hostil» 36 , este territorio «comanche» de amenaza oculta pero omnipresente que representa la situación que vivían los peruanos en aquellos años. 